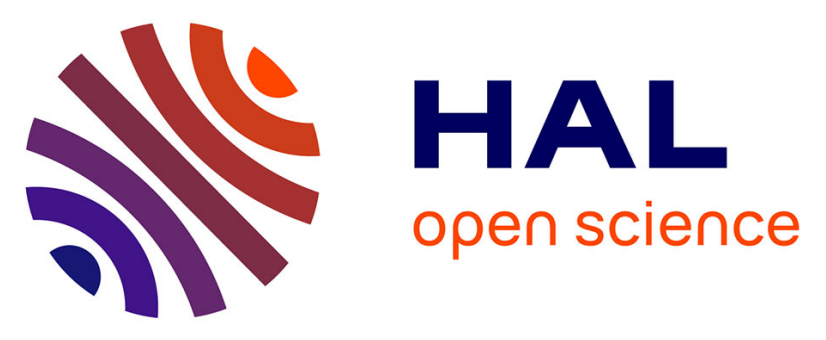

\title{
Sub-micrometer sized hairy latex particles synthesized by dispersion polymerization using hydrophilic macromolecular RAFT agents
}

\author{
Mael Bathfield, Franck d'Agosto, Roger Spitz, Marie-Therese Charreyre, \\ Christian Pichot, Thierry Delair
}

\section{To cite this version:}

Mael Bathfield, Franck d'Agosto, Roger Spitz, Marie-Therese Charreyre, Christian Pichot, et al.. Sub-micrometer sized hairy latex particles synthesized by dispersion polymerization using hydrophilic macromolecular RAFT agents. Macromolecular Rapid Communications, 2007, 28 (15), pp.1540-1545. 10.1002/marc.200700291 . hal-01877424

\section{HAL Id: hal-01877424 \\ https://hal.science/hal-01877424}

Submitted on 18 Nov 2020

HAL is a multi-disciplinary open access archive for the deposit and dissemination of scientific research documents, whether they are published or not. The documents may come from teaching and research institutions in France or abroad, or from public or private research centers.
L'archive ouverte pluridisciplinaire HAL, est destinée au dépôt et à la diffusion de documents scientifiques de niveau recherche, publiés ou non, émanant des établissements d'enseignement et de recherche français ou étrangers, des laboratoires publics ou privés. 


\title{
Sub-micron size hairy latex particles synthesized by dispersion
}

\section{polymerization using hydrophilic macromolecular RAFT agents.}

\author{
Maël Bathfield, ${ }^{1,2}$ Franck D'Agosto, ${ }^{* 1}$ Roger Spitz, ${ }^{1}$ Marie-Thérèse Charreyre, ${ }^{* 2}$
}

Christian Pichot, ${ }^{2}$ Thierry Delair ${ }^{2}$

This is a post-peer-review, pre-copyedit version

(i.e. the current layout was made by the authors)

of an article published in Macromolecular Rapid Communications.

The final authenticated version is available online at:

https://doi.org/10.1002/marc.200700291

\section{GRAPHICAL TOC}

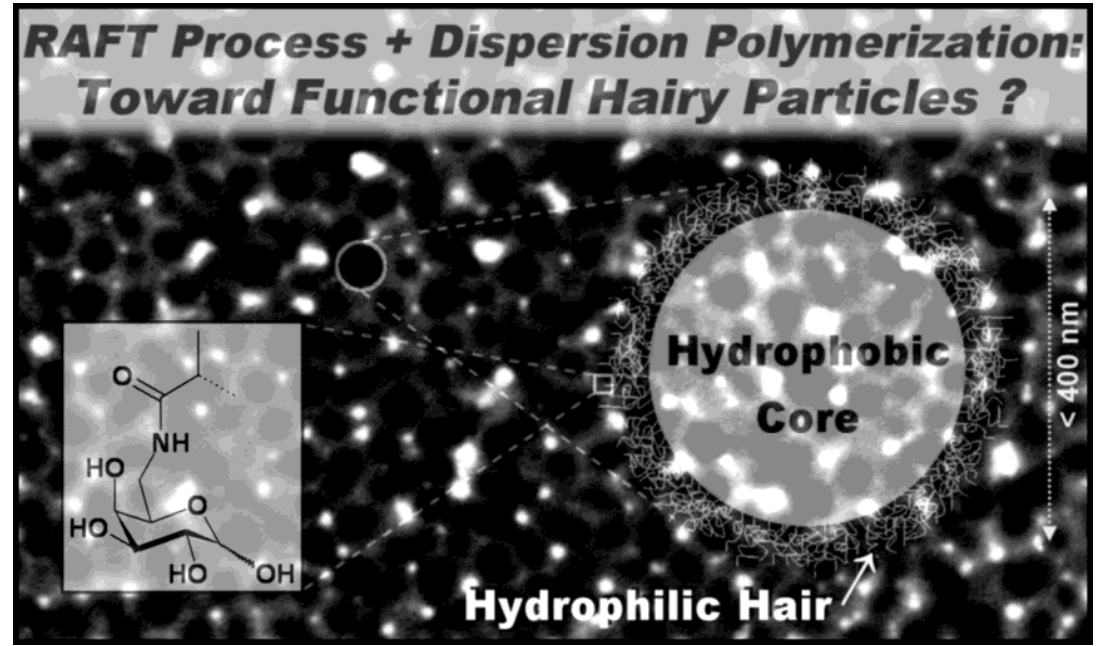




\title{
Sub-micron size hairy latex particles synthesized by dispersion
} polymerization using hydrophilic macromolecular RAFT agents.

Maël Bathfield, ${ }^{1,2}$ Franck D'Agosto, ${ }^{* 1}$ Roger Spitz, ${ }^{1}$ Marie-Thérèse Charreyre, ${ }^{* 2}$

\author{
Christian Pichot, ${ }^{2}$ Thierry Delair ${ }^{2}$
}

1. Laboratoire de Chimie et Procédés de Polymérisation UMR 140 CNRS/ESCPE, Bât 308 F, 43 Boulevard du 11 Novembre 1918, BP 2077, 69616 Villeurbanne CEDEX, France

2. Unité Mixte CNRS/bioMérieux, École Normale Supérieure de Lyon, 46 allée d'Italie, 69364 Lyon Cedex 07, France

Corresponding Authors: F. D'Agosto (Tel: 3347243 1770, Fax: 3347343 1768)

(dagosto@lcpp.cpe.fr) M.T. Charreyre (Tel: 3347272 8356, Fax: 3347272 8369) (mtcharre@ens-lyon.fr) 


\section{Keywords}

Dispersion polymerization, Reversible Addition Fragmentation chain Transfer (RAFT), macromolecular chain transfer agent (macro-CTA), latex, hairy latex particles, carbohydrate chain end.

\section{Summary}

Dispersion polymerization of $n$-butyl acrylate was performed in a mixture of ethanol and water in presence of poly(N-acryloylmorpholine) (polyNAM). These hydrophilic polymer chains were synthesized by the RAFT process and thus incorporated well-defined chain ends. The dithioester $\omega$-end group was used as an efficient chain transfer agent under dispersion polymerization conditions to produce hairy $\operatorname{poly}(n$-butyl acrylate) latex particles. Moreover, pre-functionalization of the polyNAM chains on the $\alpha$-end by a carbohydrate derivative was additionally achieved to get directly functional particles according to the same strategy.

\section{Introduction}

Dispersion polymerization has long been used to prepare micron or sub-micron sized polymer particles. ${ }^{1}$ Basically, this type of polymerization can be considered as a precipitation polymerization starting in most of the cases with an initially homogeneous reaction mixture. As polymerization proceeds, the polymer separates out and the reaction continues in a heterogeneous manner. Flocculation is indeed prevented owing to the presence of a steric stabilizer. The most efficient steric stabilizers are based on block or graft copolymers incorporating a segment soluble in the dispersing solvent and a segment being adsorbed or anchored onto the dispersed phase. These steric stabilizers can sometimes be formed in situ by grafting (transfer reaction) onto a precursor, the latter classically being a homopolymer. Poly(N-vinylpyrrolidone) (PVP) or hydroxypropylcellulose are for instance used for dispersion polymerization in polar media. These precursors of stabilizers are often employed 
at relatively high concentrations (from $5 \%$ to $30 \%$ in weight to monomer) but in fact, only a small fraction effectively participates to the stabilization of the formed latex. ${ }^{2}$ As an example, Wang et al. ${ }^{3}$ showed that only $6 \%$ of the introduced PVP $\left(M_{\mathrm{w}}=360000 \mathrm{~g} \cdot \mathrm{mol}^{-1}\right)$ is grafted on the surface of the final poly(n-butyl acrylate) latex particles. These low grafting yields essentially come from a low transfer constant to the polymer (from $10^{-4}$ to $10^{-3}$ ). ${ }^{4}$ As the grafting reactions occur along the chains of the precursor of stabilizer, the produced stabilizers are grafted copolymers. An alternative approach consisting in producing block copolymers has also been investigated. In this particular case, the chain transfer group is specifically located at the chain end of the precursor of stabilizer. Thiol-terminated poly(vinyl acetate-co-vinyl alcohol $)^{5}$ or poly(ethylene oxide $)^{6}$ have for instance been proved efficient for the dispersion polymerization of styrene.

Among the different chain transfer agents (CTA), dithioester compounds (of the general formula $\mathrm{Z}-\mathrm{C}(=\mathrm{S})-\mathrm{SR})$ are extremely efficient when the $\mathrm{Z}$ and $\mathrm{R}$ groups are adequately chosen. Indeed, the transfer reaction being reversible is at the origin of one of the most powerful controlled polymerization techniques, the RAFT process. $^{7}$ In the presence of a dithioester compound (the RAFT agent), chains undergo successive active/dormant cycles that minimize the proportion of irreversibly terminated chains with respect to the overall population and lead to a simultaneous growth of the polymer chains. In addition, the resulting well defined polymer chains are characterized by a dithioester $\omega$-chain end functionality. As such, they can subsequently serve as building blocks for the polymerization of a second monomer and thus appear as adequate candidates for use under dispersion polymerization conditions.

With respect to the reactivity of their dithioester chain end toward radicals, polymer chains synthesized by the RAFT process (macro-RAFT agents) have already been successfully used as lone precursors of stabilizers under emulsion polymerization conditions. ${ }^{8,9}$ This communication aims at focusing on the first experiments carried out under dispersion 
polymerization conditions with macro-RAFT agents as lone precursors of stabilizers. As our ultimate goal was not to control the polymerization inside the particles but to reach functional latex particles exhibiting bio-related surface groups, the proposed strategy was applied to the synthesis of hairy latex particles incorporating a carbohydrate derivative. This was achieved by synthesizing a macro-RAFT agent in the presence of a sugar-containing RAFT agent and through its subsequent use as precursor of stabilizer in dispersion polymerization.

\section{Experimental Part}

Dispersion polymerization procedure. $n$-Butyl acrylate (n-BA, 1 g), stabilizer precursors (PVP, poly(NAM) or poly(NAM)-CTA) (300 mg), 4,4'-azobis(4-cyanopentanoic) acid (ACPA, $1.87 \mathrm{mg})$, ethanol $(6.6 \mathrm{~mL})$, water $(3.5 \mathrm{~mL})$ and trioxane $(60 \mathrm{mg}$, internal reference for ${ }^{1} \mathrm{H}$ NMR determination of monomer consumption) were introduced in a $50 \mathrm{~mL}$ roundbottom flask equipped with a magnetic stirrer. The mixture was degassed by four freezeevacuate-thaw cycles and then heated under argon in a thermostated oil bath $\left(70^{\circ} \mathrm{C}\right)$. Periodically, samples were withdrawn from the polymerization medium for analyses.

Macro-RAFT agent structures, synthesis and characterization procedures as well as the characterization of the final latexes are available as Supporting Information.

\section{Results and Discussion}

Dispersion polymerization of $n-B A$ using poly(NAM) as precursor of stabilizer. BourgeatLami et al. showed that, when using in a dispersion polymerization, chain transfer groups such as thiol functions located at the end of polymer chains, less than $15 \%$ of the chains were grafted onto the final latex particles. ${ }^{6}$ The authors assumed that this low grafting yield was due to an important chain transfer activity at the beginning of the polymerization limiting the molar mass of the generated block copolymers that remained mostly soluble in the continuous 
phase. When using macro-RAFT agents and as long as the experimental conditions are close to RAFT polymerization conditions, this should not be the case since the limitation of termination reactions prevents the majority of the chains from chain stopping events. Although our goal was not to control the polymerization inside the particles, a particular attention should be paid to the initiator concentration. To ensure a simultaneous growth of the macro-RAFT chains and thus to favor a homogeneous nucleation, a low radical flux is required. Consequently, the high initiator concentration (1 to $2 \%$ weight/monomer) commonly used in dispersion polymerization should be decreased here.

n-Butyl acrylate dispersion polymerization was performed in an ethanol/water mixture (60/40 $\mathrm{w} / \mathrm{w})$ at $70^{\circ} \mathrm{C}$ using $\mathrm{ACPA}$ as initiator and in the presence of preformed poly $(\mathrm{N}$ acryloylmorpholine) chains synthesized by RAFT polymerization. As a reference experiment, we started with an adapted recipe from Wang et al. ${ }^{3}$, using PVP as precursor of stabilizer and decreasing the ACPA concentration from $1.0 \%$ to $0.18 \%$ (L1 and L2, respectively, in Table 1). To evaluate the transfer ability of poly(NAM) polymer under these conditions, a control experiment, L3, was also carried out under exactly the same conditions as L2 but using poly(NAM) chains obtained by conventional free radical polymerization (poly $(\mathrm{NAM}), M_{\mathrm{n}}=$ 54000 g.mol ${ }^{-1}$ ) instead of PVP as precursor of stabilizer. The experiment, L4, was performed in the presence of poly(NAM) chains obtained by RAFT polymerization (poly(NAM)-CTA, $\left.M_{\mathrm{n}}=38100 \mathrm{~g} \cdot \mathrm{mol}^{-1}, \mathrm{PDI}=1.06\right)$ according to conditions depicted in literature. ${ }^{10}$

As shown in Figure 1, dispersion polymerizations conducted in presence of PVP (L1 and L2) were relatively fast compared to L4 since $80 \%$ conversion was reached within 24 hours. The decrease in initiator concentration from $1 \%$ to $0.18 \%$ did not seem to strongly affect the kinetics. The initially transparent medium became turbid after 10 minutes evidencing the nucleation step. As shown in Table 1, and as expected for a dispersion process, latexes exhibiting particle sizes in the range $1000-1500 \mathrm{~nm}$ were obtained. The dispersion 
polymerization L3 performed with poly(NAM) chains synthesized by conventional free radical polymerization showed that poly(NAM) can act as a precursor of stabilizer under these conditions since particles were formed. However, the chain transfer activity along the chains being really low (possibly induced by the morpholino side group), resulted in the production of very large particles (3300 $\mathrm{nm}$ in size) due to an absence of colloidal stability. Alternatively, when performing the dispersion polymerization in the presence of poly(NAM) chains synthesized by RAFT, poly(NAM)-CTA (L4), drastic changes were observed. The polymerization medium remained limpid for more than 5 hours and a long induction period was observed on Figure 1 (about 15 h). After 24 hours of polymerization, only $29 \%$ conversion was reached. After adding initiator (same relative quantity as in L4) and subsequent degassing, the latex was reinitiated and conversion was increased to $89 \%$ (L5).

Differences in kinetics and particle size for L4 compared to L1, L2 and L3 suggested a positive involvement of the poly(NAM)-CTA used in this experiment. A correlation between nucleation step, induction period and $n$-BA RAFT block copolymerization is difficult to establish at this stage of the study since a careful characterization of the species produced at the beginning of the process is required (work in progress). However, the absence of particle formation at the early stage of the polymerization and the long induction period (L4) is a strong indication that chain transfer reactions are taking place in the continuous phase due to the presence of the dithioester chain end of the poly(NAM)-CTA. This indeed should explain the much smaller particle size observed for L5 (360 nm) (corresponding to a reinitiation of L4 to reach the same conversion as L1-3) compared to L1-3 (between 1200 and $3300 \mathrm{~nm}$ ).

Centrifugation of L5 and analysis of the resulting supernatant by ${ }^{1} \mathrm{H}$ NMR revealed the presence of residual poly(NAM) chains in the continuous phase (45\% of the introduced amount). Thus, $55 \%$ of the introduced poly(NAM)-CTA chains seemed to be involved in the 
formation of the particles, a value much higher than that reported in the case of chains with a thiol $\omega$-end-group $(15 \%){ }^{6}$

The very good colloidal stability of L4 and L5 was confirmed by the absence of any sedimentation or aggregation after several months of storage (see table 1 in SI). This strong stability was also evidenced when L4 was submitted to four successive freeze-thaw cycles or to several centrifugation-redispersion steps without any irreversible particle flocculation.

Characterization of poly(NAM) hairy layer. The high glass transition temperature $\left(\mathrm{T}_{\mathrm{g}}\right)$ of poly(NAM) $(420 \mathrm{~K})^{11}$ together with the large amount of poly(NAM) chains introduced at the periphery of the latex should prevent any film formation of the low $\mathrm{T}_{\mathrm{g}} \operatorname{poly}(n-\mathrm{BA})(230 \mathrm{~K})$. TEM technique at room temperature is generally not well suited for the observation of a $\operatorname{poly}(n-\mathrm{BA})$ latex (so as for any "soft" latex) that not only film-casts under the electron beam but also does not present a significant electronic density to provide a good contrast enough. Still, as shown in Figure 2, when analyzing L5 by TEM, the observation of particles - with a range of size consistent with the experimental values obtained by Dynamic Light Scattering is in agreement with the presence of a "hard" hairy poly(NAM) layer around the soft poly $(n$ BA) core.

This hairy layer was tentatively analyzed by NMR of the latex itself (after careful cleaning by centrifugation) by both ${ }^{1} \mathrm{H}$ and ${ }^{13} \mathrm{C}$ NMR. Indeed, in the particular case of hairy latexes, resonances of the highly mobile hydrophilic polymer chains constituting the hairs may be observed while the hydrophobic core remains not (or slightly) visible. ${ }^{12-14}$ However, it requires that the polymer chains inside the particles exhibit a $T_{g}$ high enough compared to the temperature of the NMR analysis to avoid any corresponding resonances. As an example, insitu ${ }^{1} \mathrm{H}$ NMR analyses performed on polystyrene latex particles $\left(\mathrm{T}_{\mathrm{g}}\right.$ around $\left.100^{\circ} \mathrm{C}\right)$ had been successfully employed to confirm the surface incorporation of a poly(NAM) hair. ${ }^{14}$ 
As expected, the low $\mathrm{T}_{\mathrm{g}}\left(-40^{\circ} \mathrm{C}\right)$ of $\operatorname{poly}(n-\mathrm{BA})$ does not favor an accurate ${ }^{1} \mathrm{H}$ NMR analysis since the hydrophilic grafted poly(NAM) chains and the poly $(n-\mathrm{BA})$ chains overlapped. As a result, only broad resonances corresponding to $\operatorname{poly}(n-\mathrm{BA})$ were observed (results not shown). However, this drawback was overcome when performing ${ }^{13} \mathrm{C}$ NMR (Figure 3). Analysis of the hairy latex showed the expected resonances for $\operatorname{poly}(n-\mathrm{BA})$ chains (see Supporting Information). Additional very small resonances (at $66.9 \mathrm{ppm}, 46.5 \mathrm{ppm}, 44.0$ and between 32.0 and $36.0 \mathrm{ppm}$ ) were also observed. By comparison with the spectrum of the pure poly(NAM)-CTA used to synthesize the latex, these small resonances could be assigned to poly(NAM) chains (Figure 3).

Toward saccharidic functional particles. As our ultimate goal was to elaborate functional latex particles exhibiting bio-related surface groups, we previously undertook a comprehensive research program starting with the synthesis of bio-functional CTAs and their use in RAFT polymerization. ${ }^{10,15}$ Various bio-end-functionalized polymer chains were obtained with a biotin, a sugar or a phospholipid precisely located at the $\alpha$-chain end. The polymer chains bearing a carbohydrate derivative (protected form of galactopyranose) at the chain end (sugar-poly(NAM)-CTA chains, $M_{\mathrm{n}}=29600$ g.mol ${ }^{-1}$, PDI=1.02) were subsequently used in dispersion polymerization (L6 in Table 1). For an unknown reason at this stage of the study, the nucleation step occurred earlier than for L4. However, stable latex particles were again produced $\left(D_{\mathrm{h}}=250 \mathrm{~nm}\right.$, poly $\left.=0.14\right)$ and re-dispersed in pure water $\left(D_{\mathrm{h}}=148 \mathrm{~nm}\right.$, poly $=0.14)$. The decrease of $D_{\mathrm{h}}$ after re-dispersion in pure water may result from the shrinkage of the $\operatorname{poly}(n-\mathrm{BA})$ core more likely swollen by ethanol when produced in an ethanol/water mixture. It is worth mentioning that, due to the structure of the sugar-CTA used for the synthesis of the sugar-poly(NAM)-CTA chains, the carbohydrate derivative is strongly linked to the poly(NAM) chain by a stable amide bond and that its integrity has been previously checked by MALDI-ToF MS analysis (i.e. RAFT process does not affect the structure of the 
carbohydrate derivative). ${ }^{10}$ Considering that at least $50 \%$ of the sugar-poly(NAM)-CTA chains are involved in the formation of the hairy particles and that the thickness of the hairy layer may reach $15 \mathrm{~nm}$, each particle should exhibit an average of 2400 carbohydrate moieties (Scheme 1).

\section{Conclusion}

Hydrophilic macro-RAFT agents were successfully used under dispersion conditions to take advantage of the chain transfer activity of the dithioester group located at one chain end. The in situ production of a block copolymer is an efficient way to achieve $n$-butyl acrylate dispersion polymerization in an ethanol/water mixture and leads to stable $\operatorname{poly}(n$-butyl acrylate) particles exhibiting a very significant colloidal stability. The size range of the particles that were synthesized (between 100 and $300 \mathrm{~nm}$ ) showed that the stabilizing system employed here is much more efficient than the ones generally used for dispersion polymerization where micron sized particles are prepared. In addition, a successful try was given to the synthesis of saccharadic surface functionalized poly $(n$-butyl acrylate $)$ particles by designing a hydrophilic macroRAFT agent carrying a sugar $\alpha$-end group. The large range of polymerizable monomers together with the potential of pre-functionalization using RAFT polymerization, opens the way to produce -under dispersion conditions- functional latexes achieving original properties.

\section{Supporting Information}

Experimental part and full scale ${ }^{13} \mathrm{C}$ NMR spectrum are available as Supporting Information.

\section{Acknowledgment}

The authors would like to thank Fernande Boisson (Service de RMN de la Fédération des Polyméristes Lyonnais, FR2151/CNRS, 69390 Vernaison, France.) for NMR analyses of the 
latexes, as well as G. Gody and Dr P. Boullanger for the synthesis of the amino-carbohydrate derivative.

\section{References}

[1] G. Riess, C. Labbe, Macromol. Rapid Commun. 2004, 25, 401-435.

[2] P. Lacroix-Desmazes. "Les latex synthétiques" J.-C. Daniel, Pichot,, Ed.; Tec\&Doc: Paris 2006; p. 259-288.

[3] D. Wang, V.L. Dimonie, E.D. Sudol, M.S. El-Aasser, J. Appl. Polym. Sci. 2002, 84, 2692-2709.

[4] K.C. Berger, G. Brandrup. "Polymer Handbook, 3rd edition" E. H. I. J. Brandrup, Eds., Ed.; J. Wiley \& Sons: New York 1989; p. II/81.

[5] H. Miyazaki, K. Terada, T. Sato, H. Maruyama, T. Okaya, J. Appl. Polym. Sci. 1996, 60, 2149-2157.

[6] E. Bourgeat-Lami, A. Guyot, Coll. Polym. Sci. 1997, 275, 716-729.

[7] J. Chiefari, Y.K. Chong, F. Ercole, J. Krstina, J. Jeffery, T.P.T. Le, R.T.A. Mayadunne, G.F. Meijs, C.L. Moad, G. Moad, E. Rizzardo, S.H. Thang, Macromolecules 1998, 31, 5559-5562.

[8] A.M. Dos Santos, J. Pohn, M. Lansalot, F. D'Agosto, Macromol. Rapid Commun. 2007, 28, 1325-1332.

[9] M. Manguian, M. Save, B. Charleux, Macromol. Rapid Commun. 2006, 27, 399-404.

[10] M. Bathfield, F. D'Agosto, R. Spitz, M.-T. Charreyre, T. Delair, J. Am. Chem. Soc. 2006, 128, 2546-2547.

[11] P. Peyser. "Polymer Handbook, 3rd edition" J. Brandrup, E. H. Immergut, Eds.; J. Wiley \& Sons: New York 1989; p. VI/209.

[12] M.T. Charreyre, P. Boullanger, T. Delair, B. Mandrand, C. Pichot, Coll. Polym. Sci. 1993, 271, 668-679.

[13] O. Soula, R. Petiaud, M.-F. Llauro, A. Guyot, Macromolecules 1999, 32, 6938-6943.

[14] F. D'Agosto, M.-T. Charreyre, C. Pichot, R.G. Gilbert, J. Polym. Sci., Part A: Polym. Chem. 2003, 41, 1188-1195.

[15] M. Bathfield, F. D'Agosto, R. Spitz, C. Ladaviere, M.T. Charreyre, T. Delair, Macromol. Rapid Commun. 2007, 28, 856-862. 


\section{Figures}

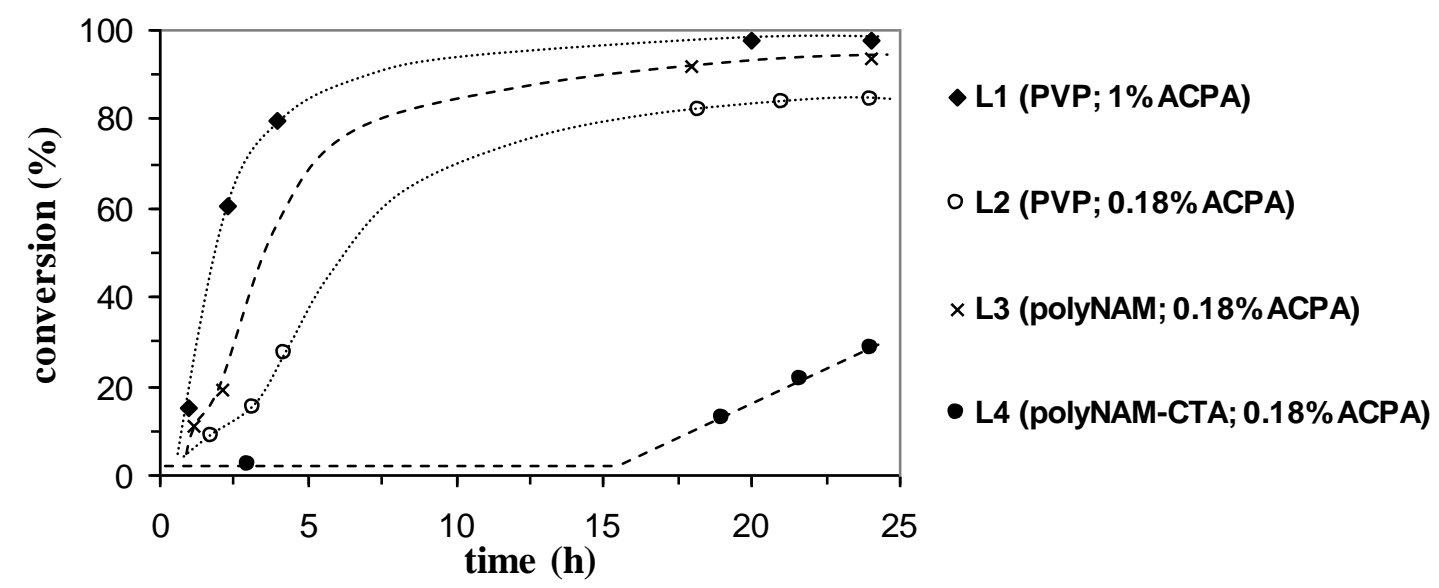

Figure 1 : Kinetics of $n$-butyl acrylate dispersion polymerization initiated by ACPA at $70^{\circ} \mathrm{C}$ in presence of different stabilizers (see Table 1, experiment L1, L2, L3 and L4). Dashed lines are only guides for the eyes.
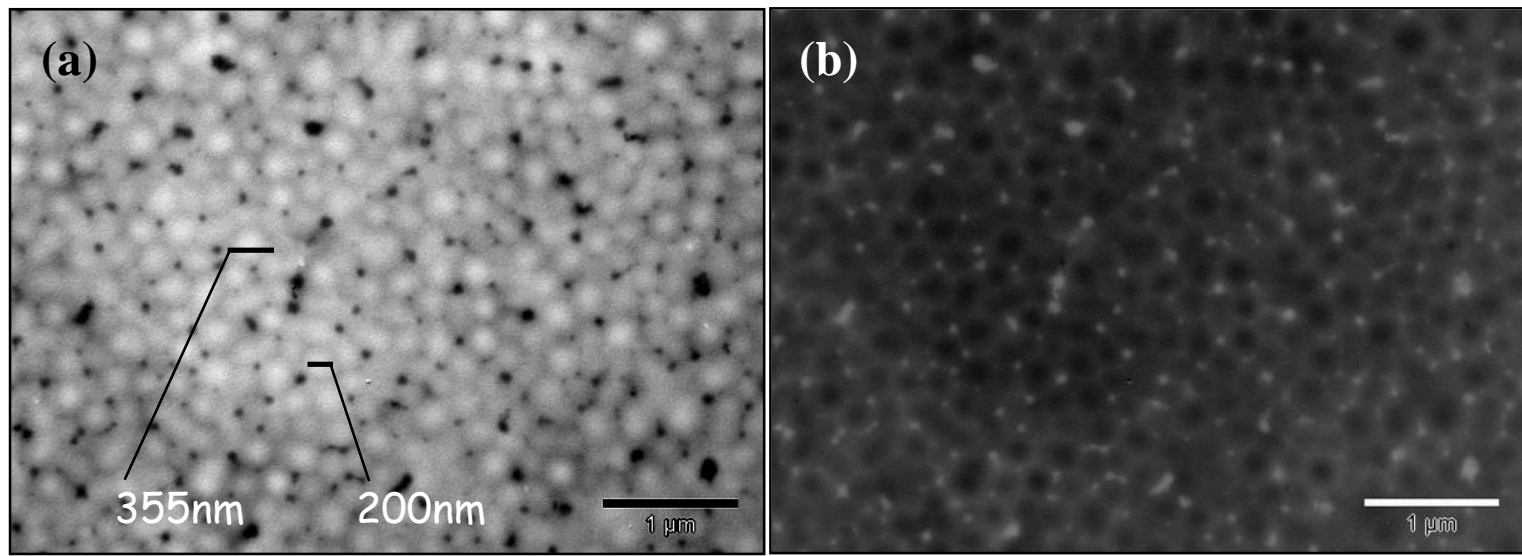

Figure 2 : TEM image of the final latex obtained by dispersion polymerization of $\boldsymbol{n}$-butyl acrylate initiated by ACPA at $7^{\circ} \mathrm{C}$ in presence of 30 wt.- $\%$ of poly(NAM)-CTA synthesized via RAFT (Table 1, Experiment L5). Initial image (a), same image in negative colors (b). 


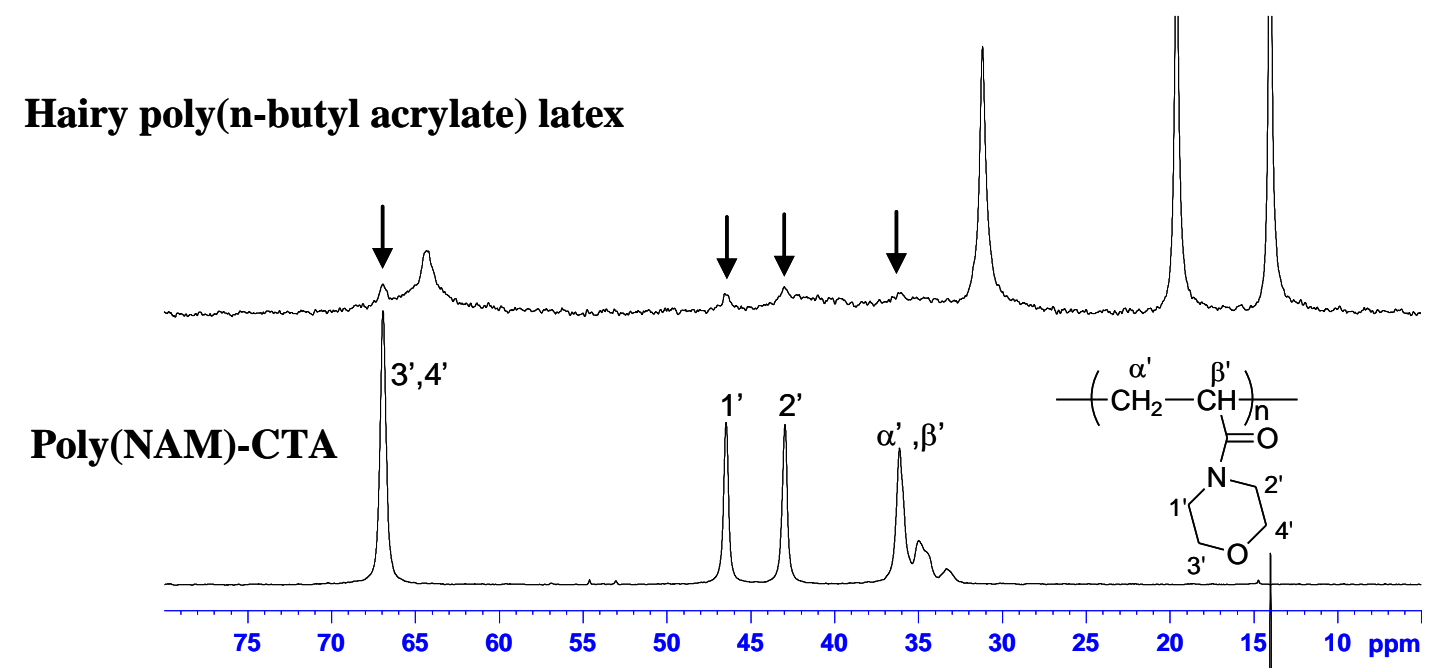

Figure 3: ${ }^{13} \mathrm{C}$ NMR analyses of hairy poly(n-butyl acrylate) latex and poly(NAM)-CTA free polymer chains used for the synthesis of the hairy latex (enlargement of the area between 5 and 80 ppm). 
Table 1 : Polymerization of $n$-butyl acrylate (n-BA, $10 \mathrm{wt.} \%$ ) in a ethanol/water mixture $(60 / 40 \mathrm{w} / \mathrm{w})$ initiated by $\mathrm{ACPA}$ at $70^{\circ} \mathrm{C}$ in the presence of various precursors of stabilizers.

\begin{tabular}{|c|c|c|c|c|c|c|}
\hline Exp. & $\begin{array}{c}\text { Stabilizer } \\
\left(M_{\mathrm{n}}\left(\text { or } M_{\mathrm{w}}\right)\left(\mathrm{g} \cdot \mathrm{mol}^{-1}\right)\right) \\
(30 \text { wt.- } \% / n-\mathrm{BA})\end{array}$ & $\begin{array}{l}\text { ACPA } \\
\text { (wt.-\% } \\
\text { ln-BA) }\end{array}$ & $\begin{array}{l}\text { Conversion } \\
\text { after } 24 \mathrm{~h}\end{array}$ & $\begin{array}{c}D_{\mathrm{h}} \\
(\mathrm{nm})\end{array}$ & $\begin{array}{c}\text { Size } \\
\text { distribution } \\
\left(\text { poly }^{a}\right)\end{array}$ & $\begin{array}{l}\text { Nucleation } \\
\text { after } \mathbf{t}_{\mathbf{o}}\end{array}$ \\
\hline L1 & PVP (40000) & 1 & $98 \%$ & 1200 & broad (1.00) & $\sim 10 \mathrm{~min}$. \\
\hline $\mathbf{L 2}$ & PVP (40000) & 0.18 & $84 \%$ & 1700 & broad (1.00) & $\sim 10 \mathrm{~min}$. \\
\hline $\mathbf{L 3}$ & poly(NAM) (54000) & 0.18 & $93 \%$ & 3300 & broad (1.00) & $\sim 10$ min. \\
\hline L4 & poly(NAM)-CTA (38100) & 0.18 & $29 \%$ & 280 & 0.06 & $\begin{array}{l}\text { after } 5 \mathrm{~h} \\
(\sim 15 \mathrm{~h})^{\mathrm{b}}\end{array}$ \\
\hline $\mathbf{L 5}^{\mathrm{c}}$ & poly(NAM)-CTA (38100) & $0.25^{\mathrm{c}}$ & $89 \%$ & 360 & 0.03 & - \\
\hline \multirow{2}{*}{ L6 } & \multirow{2}{*}{$\begin{array}{c}\text { Sugar-poly(NAM)-CTA } \\
(29600)^{\mathrm{d}}\end{array}$} & 0.18 & $51 \%$ & 200 & 0.20 & $\sim 3 \mathrm{~h}$ \\
\hline & & $0.36^{\mathrm{e}}$ & $91 \%$ & 250 & 0.14 & - \\
\hline
\end{tabular}

${ }^{a}$ See definition in Supporting Information $;{ }^{b}$ Estimated from the time-conversion curve (see Figure 1)

${ }^{\mathrm{c}}$ To increase final conversion, re-initiation of latex L4 was performed by adding $0.83 \mathrm{mg}$ of ACPA $(0.25 \mathrm{wt} \%$ compared to residual monomer) in $5 \mathrm{~mL}$ of latex. The latex was degassed by four freeze-evacuate-thaw cycles (no destabilization occurs) and then heated under argon in a thermostated oil bath $\left(70^{\circ} \mathrm{C}\right)$ during 24 hours.

${ }^{\mathrm{d}}$ Synthesized using Sugar-CTA. ${ }^{\mathrm{e}}$ Addition of initiator in polymerization medium after $24 \mathrm{~h}(0.36 \mathrm{wt} \%$ compared to residual monomer)

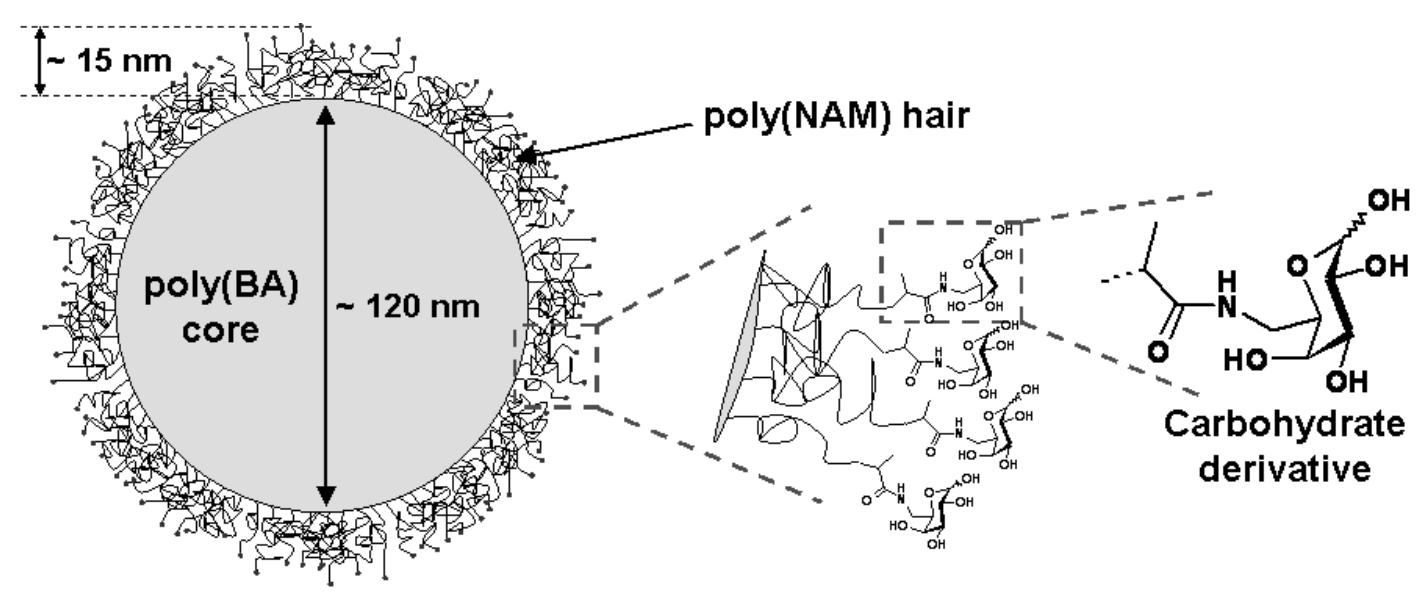

Scheme 1: Expected structure of the functional hairy particles synthesized by dispersion polymerization (after deprotection of the carbohydrate derivative). The thickness of the hairy layer indicated here is not experimental and shown only to portray its hypothetical relative size compared to the diameter of the core. 


\section{Sub-micron size hairy latex particles synthesized by dispersion}

polymerization using hydrophilic macromolecular RAFT agents.

Maël Bathfield, ${ }^{1,2}$ Franck D'Agosto, ${ }^{* 1}$ Roger Spitz, ${ }^{1}$ Marie-Thérèse Charreyre, ${ }^{* 2}$ Christian Pichot, ${ }^{2}$ Thierry Delair ${ }^{2}$

\section{Supporting Information}

1. Laboratoire de Chimie et Procédés de Polymérisation UMR 140 CNRS/ESCPE, Bât 308 F, 43 Boulevard du 11 Novembre 1918, BP 2077, 69616 Villeurbanne CEDEX, France

2. Unité Mixte CNRS/bioMérieux, École Normale Supérieure de Lyon, 46 allée d'Italie, 69364 Lyon Cedex 07, France

Corresponding Authors: F. D'Agosto (Tel: 3347243 1770, Fax: 3347343 1768) (dagosto@lcpp.cpe.fr) M.T. Charreyre (Tel: 3347272 8356, Fax: 3347272 8369) (mtcharre@ens-lyon.fr) 


\section{Experimental Part}

Materials. N-Acryloylmorpholine (NAM) (Aldrich, 97\%) was distilled under reduced pressure $\left(120^{\circ} \mathrm{C}, 10 \mathrm{mmHg}\right.$ ). 2,2'-Azobis(isobutyronitrile) (AIBN) (Fluka, 98\%) was purified by recrystallization from ethanol. 1,4-Dioxane (Acros, 99\%) was distilled over $\mathrm{LiAlH}_{4}(110$ $\left.{ }^{\circ} \mathrm{C}\right)$. $n$-Butyl acrylate (BA) was treated by passing it through inhibitor-removal columns (Inhibitor-remover, Aldrich). Trioxane (Acros, 99\%), diethyl ether (SDS, 99.5\%), 4,4'azobis-(4-cyanopentanoic acid) (ACPA, Fluka, >98\%), polyvinylpyrrolidone (PVP, $M_{\mathrm{w}}=$ 40000 g. $\mathrm{mol}^{-1}$ ) and ethanol were all used without further purification. Deionized water was used in all experiments. (N-(2-morpholinoethyl)-2-[[2-phenyl-1-thioxo]thio]-propanamide) and $\quad \mathrm{N}$-[6-desoxy-1,2:3,4-di-O-isopropylidene-6- $\alpha$-D-galactopyranosyl]-2-[[2-phenyl-1thioxoethyl]thio]-propanamide RAFT agents, (see Scheme 1, Morpholine-DT and Sugar-DT, respectively), were synthesized according to a previously published procedure. ${ }^{1}$

Macro-RAFT agent synthesis. A typical procedure is as follows. NAM (1.5 g, $10.6 \mathrm{mmol})$, Morpholine-DT (10.2 mg, $0.03 \mathrm{mmol})$, AIBN (0.49 mg, $0.003 \mathrm{mmol})$, dioxane $(5.31 \mathrm{~mL})$, and trioxane $\left(0.08 \mathrm{~g}\right.$, internal reference for ${ }^{1} \mathrm{H}$ NMR determination of monomer consumption) were introduced in a Schlenk tube equipped with a magnetic stirrer. The mixture was degassed by five freeze-evacuate-thaw cycles and then heated under nitrogen in a thermostated oil bath. Periodically, samples were withdrawn from the polymerization medium for analyses.

Polymers were precipitated in a large volume of diethyl ether then recovered by centrifugation washed three times, and finally dried under vacuum during several days before analysis by size exclusion chromatography (poly(NAM)-CTA, $M_{\mathrm{n}}=38100 \mathrm{~g} \cdot \mathrm{mol}^{-1} ; \mathrm{PDI}=1.06$, Scheme 1). 
Poly(NAM) was also obtained by free radical polymerization following the same procedure but without the use of a RAFT agent (poly(NAM), $M_{\mathrm{n}}=54000 \mathrm{~g} \cdot \mathrm{mol}^{-1} ; \mathrm{PDI}=3.1$ )

Dispersion polymerization procedure. $n$-BA (1 g), stabilizer precursors (poly(NAM)-CTA (Scheme 1), PVP or poly(NAM)) (300 mg), ACPA $(1.87 \mathrm{mg})$, ethanol $(6.6 \mathrm{~mL})$, water (3.5 $\mathrm{mL}$ ) and trioxane $\left(60 \mathrm{mg}\right.$, internal reference for ${ }^{1} \mathrm{H}$ NMR determination of monomer consumption) were introduced in a $50 \mathrm{~mL}$ round-bottomed flask equipped with a magnetic stirrer. The mixture was degassed by four freeze-evacuate-thaw cycles and then heated under argon in a thermostated oil bath $\left(70^{\circ} \mathrm{C}\right)$. Periodically, samples were withdrawn from the polymerization medium for analyses.

Monomer conversion was determined by ${ }^{1} \mathrm{H}$ NMR spectroscopy using a Bruker AC 400 spectrometer (400 MHz), by comparison of the vinylic protons (5.5-7 ppm) with trioxane (5.1 ppm) used as internal reference. ${ }^{2}$ Typically, $500 \mu \mathrm{L}$ of $d$-chloroform was added to $300 \mu \mathrm{L}$ of each crude latex sample.

Characterization of poly(NAM). Size exclusion chromatography (SEC) was performed using a Waters 510 pump and two Waters Ultrahydrogel columns (2000 and $500 \AA$ A). On-line double detection was provided by a differential refractometer (DRI Waters 410) and a three-angle $\left(47^{\circ}, 90^{\circ}, 130^{\circ}\right)$ MiniDAWN light scattering photometer (Wyatt Technologies), operating at $690 \mathrm{~nm}$. Analyses were performed by injection of $200 \mu \mathrm{L}$ of polymer solution $\left(5 \mathrm{mg} \cdot \mathrm{mL}^{-1}\right)$ in a borate buffer $\left(\mathrm{pH}=9.3,0.05 \mathrm{~mol} . \mathrm{L}^{-1}\right)$, previously filtered through a $0.22 \mu \mathrm{m}$ Millipore filter and used as eluent at a flow rate of $0.5 \mathrm{~mL} \min ^{-1}\left(35{ }^{\circ} \mathrm{C}\right)$. The specific refractive index increment $(\mathrm{dn} / \mathrm{dc})$ for poly(NAM) in the same eluent $(0.163)$ was previously determined with a NFT ScanRef monocolor interferometer operating at $633 \mathrm{~nm}$. The molar mass and polydispersity data were determined using the Wyatt ASTRA SEC/LS software package.

Characterization of the latexes. The particle size and particle size distribution were obtained by dynamic light scattering (DLS) (Zetasizer $1000 \mathrm{HS}_{\mathrm{A}}$, Malvern Instruments). The poly value 
is a dimensionless measure of the distribution broadness (defined by poly $=\mu_{2} /\langle\Gamma\rangle^{2}$, where $\mu_{2}$ is the second cumulant of correlation function fitted by the cumulants analysis and $\langle\Gamma\rangle$ is the average decay rate). For a strictly monodisperse sample, the poly value should theoretically be zero. In practice, a poly value for a "monodisperse" latex lies between 0 and 0.05. The polydispersity can be considered to have lost its significance for values above 0.15 , however below a value of 0.5 useful comparisons between samples can still be made. Samples were diluted in an ethanol/water mixture $(60 / 40 \mathrm{w} / \mathrm{w})$ before measuring the intensity of autocorrelation functions. Typically, ten independent measurements were recorded in order to determine a mean hydrodynamic diameter and a mean poly value. ${ }^{3}$

The particle morphologies were further examined by transmission electron microscopy (TEM) using a Philips CM 120 microscope working at an accelerating voltage of either 80 or $120 \mathrm{kV}$. To analyze separately the latex particles and the continuous phase, latex samples were centrifuged with an Allegra 64R Centrifuge (Beckman-Coulter) at the maximal speed (57440 G) during at least three hours. Both solids (particles) and limpid supernatant (after evaporation) were dissolved in $\mathrm{CDCl}_{3}$ and analyzed by ${ }^{1} \mathrm{H}$ NMR spectroscopy to determine the relative $\operatorname{poly}(\mathrm{NAM})$ and $\operatorname{poly}(n-\mathrm{BA})$ contents.

Direct ${ }^{1} \mathrm{H}$ and ${ }^{13} \mathrm{C}$ NMR analyses of the latex in $\mathrm{H}_{2} \mathrm{O}$ were carried out using a Bruker Avance DRX400 instrument at $400 \mathrm{MHz}$. A $5 \mathrm{~mm}$ inverse probe head, optimized for ${ }^{1} \mathrm{H}$, was used. To provide the necessary lock signal for field/frequency stabilization, an internal coaxial tube of $\mathrm{D}_{2} \mathrm{O}$ was used. Acquisition and presaturation parameters were chosen according to those of Soula et al. ${ }^{4}$ 


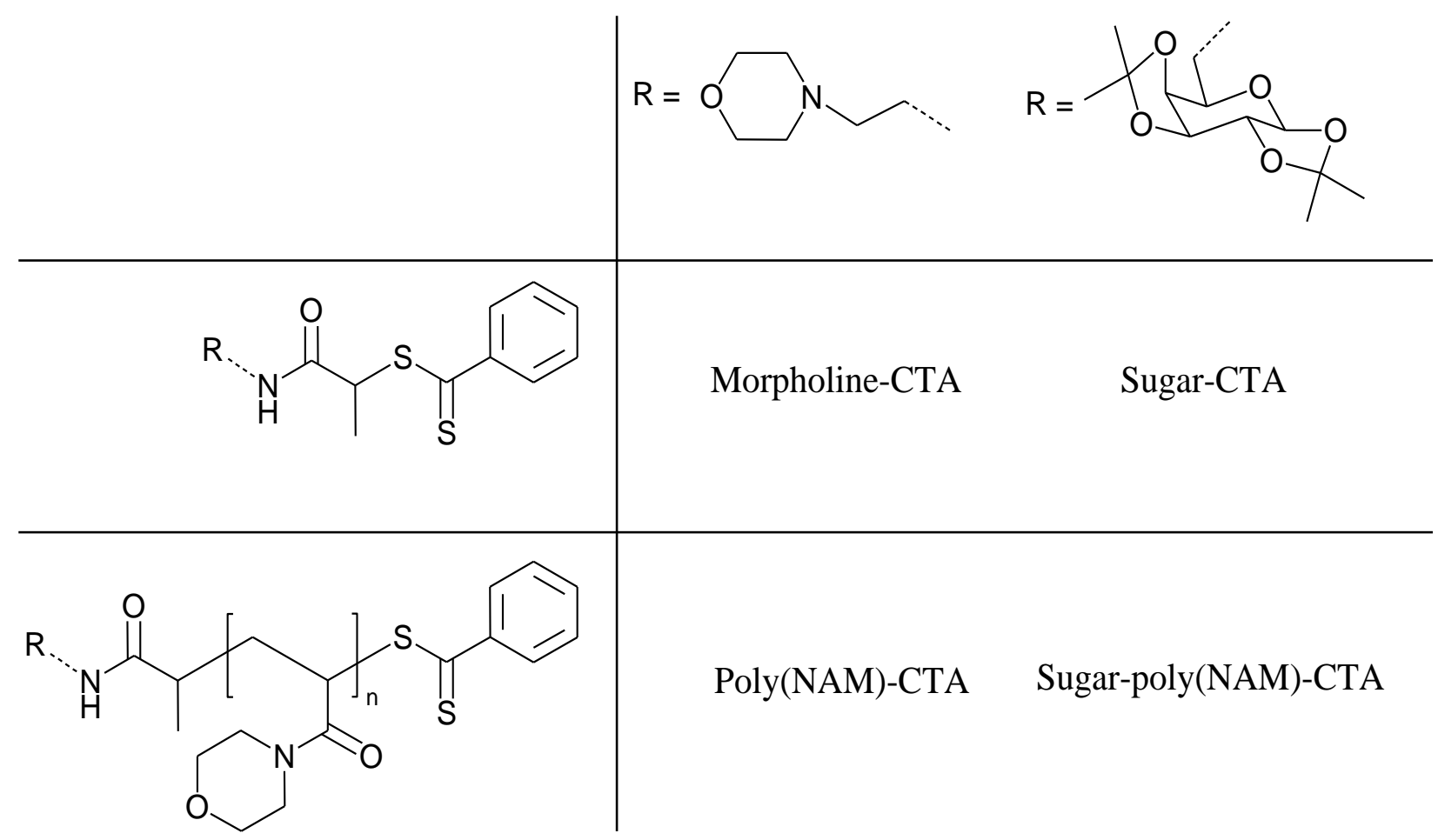

Scheme 1: Structure of the CTA and macro-CTA used in this study.

Table 1: Obtained latex (L1-5) after two days storage at room temperature.

\begin{tabular}{|c|c|c|c|c|}
\hline Experiment & L1 & L2 & L3 & L4-L5 \\
\hline Aspect of latex & & & & \\
\hline
\end{tabular}




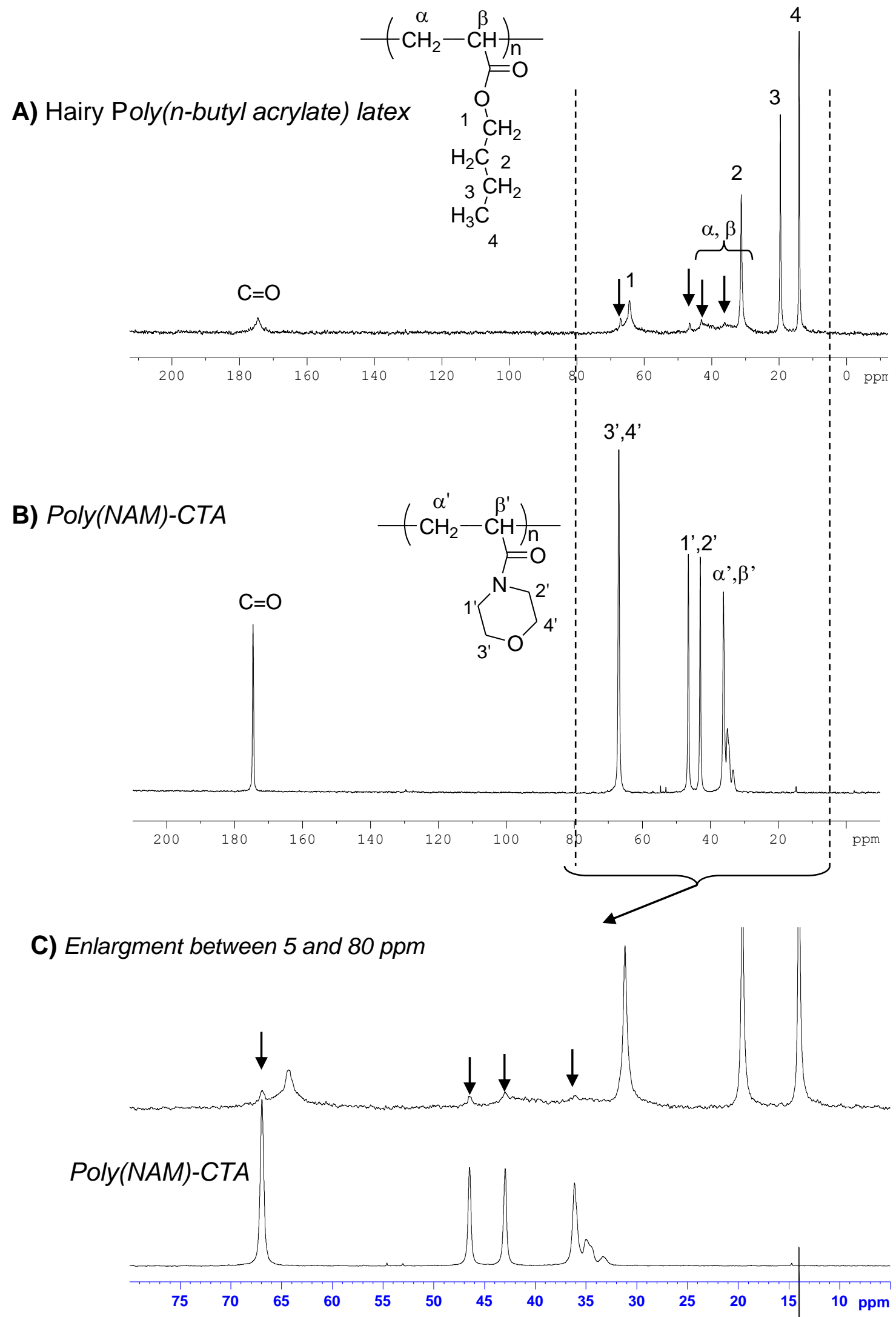

Figure 1: ${ }^{13} \mathrm{C}$ NMR analyses of $\left.A\right)$ hairy poly(n-butyl acrylate) latex and B) poly(NAM)CTA free polymer chains used for the synthesis of the hairy latex and C) enlargement of the area between 5 and 80 ppm. 


\section{References}

[1] M. Bathfield, F. D'Agosto, R. Spitz, M.-T. Charreyre, T. Delair, J. Am. Chem. Soc. 2006, 128, 2546-2547.

[2] F. D'Agosto, M.-T. Charreyre, L. Veron, M.-F. Llauro, C. Pichot, Macromol. Chem. Phys. 2001, 202, 1689-1699.

[3] A.-L. Troutier, T. Delair, C. Pichot, C. Ladaviere, Langmuir 2005, 21, 1305-1313.

[4] O. Soula, R. Petiaud, M.-F. Llauro, A. Guyot, Macromolecules 1999, 32, 6938-6943. 